\title{
Novas práticas de escrita em pesquisa qualitativa
}

\section{New Writing Practices in Qualitative Research}

Laurel Richardson $^{1}$

Tradução: Humberto Issao Sueyoshi ${ }^{2}$ 


\section{Resumo}

As novas práticas de escrita na pesquisa qualitativa incluem a escrita evocativa uma prática de pesquisa através da qual podemos investigar como construímos o mundo, nós mesmos e os outros, e como as práticas objetivadoras padronizadas da ciência social limitam desnecessariamente a nós e às ciências sociais. A linguagem é uma força constitutiva, criando uma visão particular da realidade e de si. Nenhuma encenação textual é inocente (incluindo está). Os estilos de escrita não são fixos nem neutros, mas refletem a dominação historicamente mutável de escolas ou paradigmas particulares. A escrita científica social, como todas as outras formas de escrita, é uma construção sócio-histórica e, portanto, mutável.

Palavras-chave: Escritas científicas alternativas; práticas analíticas criativas; autoetinografia

\section{Abstract}

New writing practices in qualitative research include evocative writing-a research practice through which we can investigate how we construct the world, ourselves, and others, and how standard objectifying practices of social science unnecessarily limit us and social science. Language is a constitutive force, creating a particular view of reality and the Self. No textual staging is ever innocent (including this one). Styles of writing are neither fixed nor neutral but reflect the historically shifting domination of particular schools or paradigms. Social scientific writing, like all other forms of writing, is a sociohistorical construction, and, therefore, mutable.

Keywords: Alternative scientific writings; creative analytical practices; autoethnography 


\section{Contexto Histórico: Convenções da escrita}

Desde o século XVII, o mundo da escrita foi dividido em dois tipos distintos: o literário e o científico. A literatura, a partir do século XVII, foi associada à ficção, à retórica e à subjetividade, ao passo que a ciência estava associada ao fato, à "linguagem simples" e à objetividade (Clifford, 1986, p.5). A ficção era "falsa" porque inventava a realidade, ao contrário da ciência, que era "verdadeira", porque supostamente relatava a realidade objetiva numa voz inequívoca.

Durante o século XVIII, os assaltos à literatura se intensificaram. John Locke advertiu os adultos a renunciar à linguagem figurativa, a fim de que a "conduta" entre as "coisas" e os "pensamentos" fosse obstruída. David Hume descreveu os poetas como mentirosos profissionais. Jeremy Bentham propôs que a linguagem ideal seria uma sem palavras, apenas símbolos inequívocos. O dicionário de Samuel Johnson procurou fixar "significados unívocos em perpetuidade, bem como os significados unívocos de termos aritméticos padronizados" (Levine, 1985, p.4).

Neste mundo linguístico, o Marquês de Condorcet introduziu o termo, ciência social. O marquês afirmou que o "conhecimento da verdade" seria "fácil e o erro quase impossivel" se fosse adotada uma linguagem precisa sobre as questões morais e sociais (citado em Levine, 1985, p.6). No século XIX, a literatura e a ciência eram dois domínios separados. A literatura estava alinhada com a "arte" e a "cultura"; continha os valores do "gosto, da estética, da ética, da humanidade e da moralidade" (Clifford, 1986, p.6) e os direitos à linguagem metafórica e ambígua. Dada à ciência estava a crença de que suas palavras eram objetivas, precisas, inequívocas, não-contextuais e não-metafóricas.

Mas como a escrita literária ocupava um segundo lugar em importância, posição, impacto e valor de verdade para a ciência, alguns autores literários tentaram fazer da literatura uma parte da ciência. No final do século XIX, o "realismo" dominava tanto a ciência como a escrita de ficção (Clough, 1992). Honore de Balzac encabeçou o movimento do realismo na literatura. Ele via a sociedade como um "organismo histórico" com "espécies sociais" semelhantes às "espécies zoológicas". Os escritores merecedores de louvor, segundo ele, devem investigar "as razões ou causas" dos "efeitos sociais" - os "primeiros princípios" sobre os quais a sociedade se baseia (1842/1965, pp. 247-249). Para Balzac, o romance era um "instrumento de investigação científica" (Crawford, 1951, p.7). Seguindo o exemplo de Balzac, Emile Zola defendeu o "naturalismo" na literatura. Em seu famoso ensaio "O romance como ciência social", ele argumentou que o "retorno à natureza, a evolução naturalista que marca o século, leva pouco a pouco toda a manifestação da inteligência humana para o mesmo caminho científico". A literatura seria "governada pela ciência" (1880/1965, p.271).

À medida que o século vinte se desdobrava, as relações entre a escrita científica social e a escrita literária cresciam em complexidade. As demarcações presumidamente sólidas entre "fato" e "ficção" e entre "verdadeiro" e "imaginado" eram borradas. O desfoque foi mais intensamente debatido em torno da escrita para o público - ou o jornalismo. Apelidado por Thomas Wolfe como o "Novo Jornalismo", os escritores conscientemente borraram as fronteiras entre fato e ficção e conscientemente se fizeram o centro da história (para uma excelente e extensa discussão sobre o Novo Jornalismo, ver Denzin, 1997). 
Os novos jornalistas também invadiram a província etnográfica, tomando seus métodos e relatando a vida social e cultural, não como "repórteres", mas como analistas sociais. Juntando-se aqueles intrusos estavam os escritores de ficção, como Truman Capote, Joan Didion, e Norman Mailer. Os professores de literatura despertaram e re-despertaram o interesse pelos romances de escritores minoritários e pós-coloniais, posicionando-os como "romances etnográficos" - narrativas que contam uma cultura através de personagens (Hurston, 1991).

$\mathrm{Na}$ década de 1970, os "cruzamentos" entre as formas de escrita geraram a designação de gêneros oxímorônicos: "não-ficção criativa", "facção", "ficção etnográfica", "romance de não-ficção" e "ficção verdadeira". E.L. Doctorow afirmou: "Não há mais coisas como ficção ou não-ficção, só há narrativas" (citado em Fishkin, 1985, p.7).

Sempre que há mudanças nos estilos e formatos de escrita, podemos esperar interesse intelectual em documentar e rastrear essas mudanças. Hoje, os estudiosos de uma série de disciplinas estão rastreando as relações entre a escrita científica e literária e desconstruindo as diferenças entre elas (Brodkey, 1987, Brown, 1977, Mischler, 1989, Simons, 1990). Suas análises desconstrutivas mostram concretamente como todas as disciplinas têm seu próprio conjunto de dispositivos literários - não necessariamente dispositivos de escrita de ficção - e apelos retóricos, como tabelas de probabilidade, registros de arquivos e relatos em primeira pessoa. Nas ciências sociais - incluindo as ciências sociais dos esportes - os fatos não-orientados, a prosa simples, a expectativa da narrativa linear (teoria passada, revisão de literatura, hipóteses presentes, métodos de teste, descobertas, investigação futura) limitam o que se pode saber e o que pode ser contado.

Como é esperado que se escreva afeta o que podemos escrever sobre. O sistema de referência em ciências sociais, por exemplo, desencoraja o uso de notas de rodapé, um lugar para argumentos secundários, novas conjecturas e ideias relacionadas. 0 conhecimento é constituído como focalizado, problema (hipótese) centrado, linear e direto. Outros pensamentos são estranhos. A pesquisa realizada indutivamente deve ser relatada de forma dedutiva, o argumento deve ser abstraído em 150 palavras ou menos, e os pesquisadores devem identificar-se explicitamente com um rótulo teórico. Cada uma dessas convenções favorece - cria e sustenta - uma visão particular do que constitui o conhecimento. As convenções possuem enorme poder material e simbólico sobre os cientistas sociais. Usá-los aumenta a probabilidade de um trabalho ser aceito em um "núcleo" de revistas de ciências sociais, mas eles não são uma evidência de uma maior - ou menor - prima facie ${ }^{3}$ como valor de verdade ou significado do que as escritas das ciências sociais que utilizam outras convenções.

Outras convenções de escrita em ciências sociais governaram as etnografias. Necessariamente distinguindo o seu trabalho dos relatórios dos viajantes e missionários, bem como da escrita imaginativa, os etnógrafos adotaram uma voz impessoal, de terceira pessoa para explicar um fenômeno observado e trompetear a autenticidade de suas representações. John van Maanen identifica quatro convenções usadas nas etnografias tradicionais ou "contos realistas" (1988): (a) autor(idade) experiencial, onde o autor existe apenas no prefácio para estabelecer as credencias de "Eu estava

3 Termo do latin para designar uma prova absoluta 
lá" e "Eu sou um pesquisador"; (B) estilo documental ou uma pletora de detalhes concretos e particulares que presumem representar a típica atividade, padrão ou membro da cultura; (C) o ponto de vista do membro da cultura, supostamente apresentado através de citações, explicações, sintaxe, clichês culturais, etc ;; e (d) onipotência interpretativa do etnógrafo. Muitos dos livros clássicos nas ciências sociais são contos realistas. Estes incluem Everything in its Path ${ }^{4}$ (1976) de Kai Erikson, Street Corner Society ${ }^{5}$ (1943) de William Foote Whyte e All our Kin ${ }^{6}$ (1974) de Carol Stack.

Outros gêneros de escrita qualitativa, como textos baseados em histórias de vida ou entrevistas em profundidade, têm seus próprios conjuntos de convenções tradicionais (ver Mischler, 1989; Richardson, 1990). Nesses textos qualitativos, os pesquisadores estabelecem suas credenciais na seção introdutória ou de métodos; eles escrevem o corpo do texto como se os trechos do documento e das citações estivessem naturalmente presentes, válidos, confiáveis e totalmente representativos, em vez de selecionados, podados e enfeitados pelo autor para sua aparência textual. Assim como as etnografias culturais, a assunção da autoridade científica é retórica nesses outros textos qualitativos. Exemplos de textos convencionais de "história de vida" incluem Os Worlds of Pain ${ }^{7}$ de Lillian Rubin (1976), The Ageless Self ${ }^{8}$ de Sharon Kaufman (1986) e de minha própria autoria The New Other Woman ${ }^{9}$ (1985).

\section{Contexto Pós-modernista}

Temos a sorte de trabalhar em um clima pós-modernista (Agger, 1990, Clifford \& Marcus, 1986, Denzin, 1986, 1991, 1995, Lyotard, 1979/1984, Nicholson, 1990, Richardson, 1997, Turner \& Bruner, 1986), um tempo em que uma multidão de abordagens ao conhecimento e ao dizer existem lado a lado. O núcleo do pós-modernismo é a dúvida de que qualquer método ou teoria, discurso ou gênero, tradição ou novidade, tem uma reivindicação universal e geral como a "direita" ou a forma privilegiada do conhecimento autoritário. $O$ pós-modernismo suspeita que todas as reivindicações de verdade mascaram e servem a interesses particulares de um local, uma cultura e uma luta política. Mas os métodos convencionais de saber e contar não são automaticamente rejeitados como falsos ou arcaicos. Em vez disso, esses métodos padrões são abertos à investigação, e novos métodos são introduzidos, que também estarão, então, sujeitos à crítica.

O contexto pós-modernista da dúvida, portanto, desconfia igualmente de todos os métodos. Nenhum método tem um status privilegiado. A superioridade da ciência sobre a literatura - ou de outro ponto de vista, a literatura sobre a ciência - é desafiada. Mas uma posição pós-moderna nos permite conhecer algo sem pretender saber tudo. Ter um conhecimento parcial, local, histórico ainda é conhecimento. De certa forma, saber é mais fácil, porém, isso acontece porque o pós-modernismo reconhece as limitações situacionais daquele que sabe. Os escritores qualitativos estão fora do

4 Tudo em seu caminho

5 Sociedade da esquina da rua

6 Todos os nossos parentes

7 Mundos da Dor

80 Eu Eterno

9 A nova outra mulher 
gancho, por assim dizer. Eles não têm que tentar interpretar Deus, escrevendo como narradores oniscientes incorpóreos alegando conhecimento universal, atemporal, geral; Eles podem evitar a meta-narrativa questionável da objetividade científica e ainda têm muito a dizer como oradores situados, subjetividades empenhadas em conhecer/contar sobre o mundo como eles o percebem.

Um tipo particular de pensamento pós-modernista que eu achei especialmente útil é o pós-estruturalismo (para uma visão geral, ver Weedon, 1987, para aplicação da perspectiva em um ambiente de pesquisa, ver Davies, 1994). O pós-estruturalismo liga a linguagem, a subjetividade, a organização social e ao poder. A peça central é a linguagem. A linguagem não reflete a realidade social, mas produz significado e cria a realidade social. Diferentes línguas e diferentes discursos dentro de uma dada linguagem dividem o mundo e lhe dão significado de formas que não são redutíveis umas às outras. A linguagem é como a organização social e o poder são definidos e contestados e o lugar onde se constrói o nosso sentido do eu, a nossa subjetividade. Compreender a linguagem como discursos concorrentes, formas concorrentes de dar significados e de organizar o mundo, torna a linguagem um local de exploração e luta.

A linguagem não é o resultado da individualidade, mas, sim, ela constrói a subjetividade do indivíduo de modos historicamente e localmente específicos. $\mathrm{O}$ que algo significa para os indivíduos depende dos discursos disponíveis. Por exemplo, ser atingido pelo cônjuge é diferente se é pensado dentro do discurso de "casamento normal", "direitos do marido", ou "o espancamento da esposa", Se uma mulher vê a violência masculina ou o direito do marido como normal, então é improvável que ela veja o espancamento da esposa como um uso ilegítimo de poder que não deve ser tolerado. Da mesma forma, quando um homem é exposto ao discurso de "abuso sexual na infância", ele pode re-categorizar e lembrar suas próprias experiências traumáticas da infância. A experiência e a memória, portanto, estão abertas a interpretações contraditórias, governadas por interesses sociais e discursos predominantes. $O$ indivíduo é ao mesmo tempo local e sujeito dessas lutas discursivas pela identidade e pela refilmagem da memória. Como o indivíduo está sujeito a discursos múltiplos e concorrentes em muitos reinos, a subjetividade de alguém está mudando e é contraditória, não sendo estável, fixa e rígida.

O pós-estruturalismo, portanto, aponta para a contínua co-criação do eu e das ciências sociais; eles são conhecidos entre si. Conhecer o eu e conhecer o assunto são conhecimentos interligados, parciais, históricos e locais. O pós-estruturalismo, então, permite - não, convida, não, incita - que nós reflitamos sobre nosso método e exploremos novas maneiras de conhecer.

Especificamente, o pós-estruturalismo sugere duas coisas importantes aos escritores qualitativos: primeiro, nos direciona a nos entendermos reflexivamente como pessoas que escrevem a partir de posições particulares em momentos específicos e, em segundo lugar, nos liberta de tentar escrever um único texto em que tudo seja dito ao mesmo tempo para todos. Cultivar nossas próprias vozes libera o domínio censurável da "escrita da ciência" em nossa consciência, bem como a arrogância que ele promove em nossa psique: a escrita é validada como um método de conhecer. 


\section{Práticas Analíticas Criativas: Etnografias PAC (CAP Ethnography)}

$\mathrm{Na}$ esteira da crítica pós-modernista - incluindo a pós-estruturalista, a feminista, a queer e a teoria crítica da raça - de práticas de escrita qualitativa tradicional, o trabalho qualitativo agora aparece em vários locais em diferentes formas. A prosa da escrita da ciência não é sacrossanta. O gênero etnográfico tem sido borrado, ampliado e alterado para incluir a poesia, o drama, as conversas, os leitores de teatro e assim por diante. Essas etnografias são semelhantes entre si pelo fato de serem produzidas através de práticas analíticas criativas.

Eu tenho estabelecido esta classe de etnografias como, Etnografias práticas analíticas criativas ou Etnografias PAC. Este rótulo pode incluir trabalhos novos, trabalhos futuros e trabalhos mais antigos, onde quer que o autor tenha se movido para fora da escrita social e científica convencional.

Eu sei que qualquer conceito ou acrônimo é problemático e sujeito a crítica. No entanto, quanto mais eu pensava sobre o nome dessas etnografias de gênero, mais eu gostava das complexas ressonâncias metafóricas do acrônimo, PAC $\left(C A P^{10}\right)$. CAP vem do latim para cabeça, caput. Usar a cabeça para sinalizar o trabalho de brecha etnográfica pode ajudar a quebrar a dualidade mente/corpo. A cabeça é mente e corpo e também mais. Produtores de etnografias PAC estão usando suas cabeças. Os produtos, embora mediados por todo o corpo, não podem se manifestar sem o trabalho da cabeça.

O PAC (CAP) - como substantivo (produto) e verbo (processo) - tem múltiplos significados e associações comuns e idiomáticas, algumas dos quais refratam a brincadeira do gênero: uma cobertura de cabeça arredondada; uma capa de cabeça especial, a indicação de uma ocupação ou o membro em uma sociedade ou em um grupo particular; o topo de um edifício ou fungo; uma pequena carga explosiva; qualquer um dos vários tamanhos de papel para escrever; a ação de dar os toques finais; deitado em cima de; superando; ou ultrapassando. E então, há as outras palavras associadas à raiz latina, como capilar e capital(ismo), que rebaixam e contextualizam o trabalho.

As práticas que produzem as etnografias PAC são ambas criativas e analíticas. Qualquer crença dinossauriana de que "criativo" e "analítico" são modos contraditórios e incompatíveis estão no caminho de um meteoro. Eles estão condenados à extinção. Por exemplo, a evolução, a proliferação e a diversidade de novas "espécies" etnográficas durante as últimas duas décadas incluem: autoetnografia (e.g., Behar, 1996, Bruner, 1996, Church, 1995, Ellis, 1993); Histórias de ficção (e.g., Cherry, 1995, Diversi, 1998, Frohock, 1992); Poesia (e.g., Baff, 1997, Brady, 1991, Diamond, 1985, Glesne, 1997); Drama (e.g., Ellis e Bochner, 1991, Paget, 1990, Richardson e Lockridge, 1991, Richardson, 1993, 1996a); textos performáticos (e.g., Denzin, 1997, McCall e Becker, 1990, Mienczakowski, 1996); escritura de histórias (e.g., Richardson 1995, 1997, St. Pierre, 1997); gêneros mistos (e.g., Brown, 1991, Davies, 1989, Fine, 1992, Hooks, 1990, Jones, 1998, Lather, 1991, Stoller, 1989, Ulmer, 1989); e assim por diante.

Por mais de uma década, o que chamo de etnografias PAC foram rotuladas como experimentais ou alternativas (Van Maanen, 1995). Não intencionalmente,

10 Na língua original o acrônimo é PAC e poderia ser traduzido como boné, capuz, topo 
porém, esses rótulos reinscreveram as práticas etnográficas tradicionais como padrão - o modo conhecido, aceito, preferido, experimentado e verdadeiro de fazer e representar a pesquisa qualitativa. Creio que a re-inscrição agora é desnecessária, falsa e deletéria. As etnografias PAC não são alternativas ou experimentais; elas são, por si mesmas, representações válidas e desejáveis do social. No futuro previsível, essas etnografias podem ser, de fato, as representações mais válidas e desejáveis, pois abrem espaços para pensar o social que agora nos escapa.

As etnografias PAC mostram o processo de escrita e o produto da escrita como profundamente entrelaçados; Ambos são privilegiados. O produto não pode ser separado do produtor ou o modo de produção ou o método do saber. Uma vez que todas as pesquisas - a etnografia tradicional e a PAC - são agora produzidas dentro do clima pós-moderno mais amplo de "dúvida", os leitores (e revisores) querem e merecem saber como o pesquisador afirma saber. Como o autor posiciona o eu como um "conhecedor" e um narrador? Essas questões envolvem de um lado os problemas interligados da subjetividade, autoridade, autoria, reflexividade e processo, e por outro lado a forma representacional.

O pós-modernismo afirma que a escrita é sempre parcial, local e situacional e que o nosso eu está sempre presente, não importa o quanto tentemos suprimi-lo - mas apenas parcialmente presente, pois em nossa escrita reprimimos partes de nós mesmos também. Trabalhar a partir dessa premissa nos liberta para escrever o material de várias maneiras: contar e recontar. Não existe tal coisa como "entendê-lo direito", apenas "entendê-lo" contornado e matizado diferentemente. Ao usar as práticas analíticas criativas, os etnógrafos aprendem sobre o tema e sobre si mesmos o que era incognoscível e inimaginável usando procedimentos analíticos, metáforas e formatos de escrita convencionais. Mesmo que se queira escrever um artigo de forma convencional, tentar diferentes modos de escrever é uma maneira prática e poderosa de expandir as habilidades interpretativas, elevar a consciência e trazer uma nova perspectiva para a pesquisa.

Está além do escopo deste artigo delinear ou comentar o placar das novas práticas etnográficas e formas. Além disso, está muito além do escopo deste artigo discutir as práticas que excedem as páginas escritas - performances, teatro de leitores, exposições de museus, achados de pesquisas coreografadas, representações de belas artes, hipertextos, e assim por diante - embora eu de as boas vindas a essas adições para o repertório qualitativo e acredite que elas estão na vanguarda do nosso futuro etnográfico. Em vez disso, vou abordar uma série de gêneros que implantam dispositivos literários para recriar a experiência vivida e evocar respostas emocionais. Eu chamo elas de representações evocativas. Resisto a fornecer ao leitor trechos dessas formas porque os trechos não lhes farão justiça. Eu descrevo alguns textos, mas não tenho nenhum desejo de valorizar um novo cânone. Novamente, uma discussão sobre o processo em vez de produto é o objetivo deste artigo.

As representações evocativas são uma maneira impressionante de ver através e além dos naturalismos científicos sociais. Lançar a ciência social em formas evocativas revela a retórica e o trabalho subjacente da produção, bem como o potencial das ciências sociais como um esforço humano, porque a escrita evocativa nos toca onde vivemos, em nossos corpos. Através dela podemos experimentar o processo auto 
reflexivo e transformacional da autocriação. Experimentando formas evocativas, relacionamo-nos de forma diferente com o nosso material; nós o sabemos diferente. Encontramo-nos atendendo a sentimentos, ambiguidades, sequências temporais, experiências turvas e assim por diante; Nós lutamos para encontrar um lugar textual para nós mesmos, nossas dúvidas e nossas incertezas (e.g., ver Bruce, Denison, Tsang e Wood neste número da SSJ).

Uma forma de escrita evocativa é a autoetnografia. Estes são altamente personalizados, revelando textos em que os autores contam histórias sobre suas próprias experiências vividas, relacionando o pessoal com o cultural. O poder dessas narrativas depende de sua apresentação retórica como "histórias verdadeiras", histórias sobre eventos que realmente aconteceram ao escritor. Ao narrar a história, o escritor invoca tais técnicas de escrita de ficção como imagens dramáticas recalcadas, imagens fortes, personagens esboçados, fraseios incomuns, trocadilhos, subtextos, alusões, recordações, antecipações, mudanças de tom, sinédoques, diálogos e monólogos interiores. Através dessas técnicas, o escritor constrói uma sequência de eventos, um "enredo", retendo a interpretação, pedindo ao leitor que "assista" emocionalmente os eventos com o escritor. Essas narrativas procuram atender aos critérios literários de coerência, verossimilhança e interesse. Algumas narrativas do eu são encenadas como representações imaginativas; outras são encenadas como ensaios pessoais, buscando a honestidade, a revelação e o "quadro maior". Em ambos os casos, os etnógrafos estão um pouco aliviados dos problemas de falar pelo "outro", porque eles são o outro em seus textos.

Relacionadas com a autoetnografia, sem invocar necessariamente as estratégias de escrita mencionadas acima, são narrativas sobre o próprio processo de escrita. Eu chamo elas de escritura de histórias (e.g., veja Sparkes neste número). São narrativas sobre contextos nos quais a escrita é produzida. Eles situam a própria escrita em outras partes da vida, como restrições disciplinares, debates acadêmicos, políticas departamentais, movimentos sociais, estruturas comunitárias, interesses de pesquisa, laços familiares e histórias pessoais. Eles oferecem reflexividade crítica sobre o auto-escrita em diferentes contextos como uma prática analítica criativa valiosa. Eles evocam novas questões sobre o eu e o sujeito; eles nos lembram que nosso trabalho é fundamentado, contextual e rizomático. Podem evocar partes mais profundas de si, curar feridas, realçar o sentido do eu - ou mesmo alterar um senso da identidade.

Ao contrário das duas formas acima, uma forma evocativa sobre a qual há literatura extensa é a ficção etnográfica (ver Banks e Banks, 1998). Escrita de ficção, que de acordo com o escritor Ernest Lockridge, "está usando a imaginação para descobrir e encarnar a verdade" (comunicação pessoal, 10 de março de 1998). Os escritores das ciências sociais que afirmam que seu trabalho é ficção privilegiam sua imaginação, procurando expressar suas visões da verdade sócio-científica. Em geral, eles encerram sua história - seja sobre si mesmos ou sobre um grupo ou cultura - em um ambiente que estudaram etnográficamente; As normas culturais são promulgadas através dos personagens. Além das técnicas utilizadas pelos auto-narradores (ver acima), os escritores de ficção etnográfica podem recorrer a outros dispositivos, como pontos de vista alternativos, caracterização profunda, voz em terceira pessoa e ao narrador onisciente. Não creio que nenhum escritor de ficção etnográfica escreva do ponto de vista do narrador não confiável (Lockridge, 1987). 
Existem algumas vantagens e algumas desvantagens em afirmar que a escrita etnográfica é ficção. Encenar a pesquisa qualitativa como ficção libera o autor de algumas limitações, protege o autor de acusações criminais ou outras, e pode proteger as identidades dos estudados. No entanto, competir no mundo editorial da ficção literária é muito difícil; poucos conseguem. Além disso, se seu desejo é efetuar a mudança social através de sua pesquisa, a ficção é uma estratégia de escrita retoricamente ruim. Os formuladores de políticas preferem materiais que afirmam não ser não-ficção mesmo, mas "verdadeira pesquisa".

A representação poética, como diz Robert Frost, é "a distância emocional mais curta entre dois pontos" - o orador e o leitor. Escrever entrevistas sociológicas como poesia, por exemplo, mostra o papel do tropo de prosa na constituição do conhecimento. Quando lemos ou ouvimos poesia, somos continuamente empurrados para reconhecer que o texto foi construído. Mas todos os textos são construídos, incluindo a prosa; portanto, a poesia ajuda a problematizar a confiabilidade, a validade, a transparência e a verdade.

Escrever dados como representações poéticas revela a crença constrangedora de que o propósito de um texto de ciências sociais é transmitir informações como fatos, temas ou noções existentes independentemente do contexto em que foram encontradas ou produzidas, como se a história que gravamos, transcrevemos, editamos e escrevemos em trechos de prosa são as únicas verdadeiras: uma história da ciência. A escrita de prosa padrão esconde a cópia da mão do sociólogo que produziu o texto escrito final.

Além disso, quando as pessoas falam, sejam conversadores, contadores de histórias, informantes ou entrevistados, seu discurso está mais próximo da poesia do que da prosa sociológica (Tedlock, 1983). Escrever entrevistas como poemas, honra as pausas do orador, as repetições, as aliterações, as estratégias narrativas, os ritmos e assim por diante podendo realmente representar melhor o orador do que a prática de citar em trechos de prosa. Além disso, os dispositivos poéticos - ritmos, silêncios, espaços, pontos de respiração, aliterações, métricas, cadências, assonâncias, rimas e versos brancos - envolvem o corpo do ouvinte, mesmo que a mente resista e negue. "A poesia é, acima de tudo, uma concentração do poder da linguagem que é o poder do nosso relacionamento supremo com tudo no universo. É como se as forças que não pudemos reivindicar de nenhuma outra forma se tornassem presentes a nós em forma sensual" (DeShazer, 1986, p.138). Colocar palavras juntas em novas configurações nos permite ouvir, ver e sentir o mundo em novas dimensões. A poesia, portanto, é um método prático e poderoso para analisar mundos sociais.

"A História de Sua Vida Por Louisa May" é um exemplo de construção poética que desafia pressupostos epistemológicos (Richardson, 1997). É um poema narrativo de cinco páginas que eu criei a partir de uma transcrição de 36 páginas da minha entrevista em profundidade com "Louisa May", uma mãe solteira. Ao escrever a história de Louisa May, baseei-me em critérios científicos e literários. Este foi um desafio literário maior do que sociológico, porque Louisa May não usou imagens ou palavras sensoriais e muito poucas expressões idiomáticas. O poema, portanto, teve que ser construído sobre outros dispositivos poéticos como repetição, pausas, métrica, rimas e versos brancos. Sem colocar palavras em sua boca, o que violaria minha sensibili- 
dade sociológica, usei sua voz, dicção, ritmos do sul da colina e seu tom. Escrevi sua vida - como ela me contou - como um exemplo historicamente situado de fazer sentido. Sua vida, como ela fala, é "normal". O subtexto político, como eu escrevi, é a da "Mãe Coragem na América".

O drama etnográfico é outra forma evocativa de moldar uma experiência. Sem perder a experiência: poder misturar técnicas realistas, ficcionais e poéticas; reconstruir o sentido de um evento a partir de múltiplas perspectivas "como-vividas"; permitir que as vozes conflitantes sejam ouvidas, aliviando o pesquisador de ser juiz e árbitro; e dando voz àquilo que não é dito, mas presente, por exemplo, o câncer como retratado no drama etnográfico de Paget (1990) ou o aborto como no drama de Ellis e Bochner (1991). Quando o material a ser exibido é intratável, indisciplinado, múltiplo e emocionalmente carregado, o drama é mais provável para recapturar a experiência do que a escrita padrão.

Construir um drama levanta os debates pós-modernos sobre textos orais e escritos. O que vem primeiro? Qual deve ser ou é privilegiado e com que consequências? Por que a bifurcação entre o oral e o escrito? A origem da experiência vivida, codificada como notas de campo, transformada em uma peça etnográfica, executada, gravada e depois reeditada para publicação, o roteiro impresso pode muito bem ser a versão definitiva ou válida, particularmente para aqueles que privilegiam a publicação sobre o original, o desempenho, ou mesmo a experiência vivida. O que acontece se aceitarmos essa validade? A construção dramática fornece múltiplos locais de invenção e contestação potencial de validade, a difusão de textos orais e escritos, movimentos retóricos, dilemas éticos e autoridade ou autoria. Não se trata apenas de falar sobre essas questões, são essas as questões (Richardson, 1997).

Muitas vezes, agora, as representações extraídas livremente de gêneros literários, artísticos e científicos, muitas vezes quebrando também os limites de cada um deles. Nessas produções, o pesquisador pode ter diferentes abordagens sobre o mesmo tema, o que eu penso como uma desconstrução pós-modernista da triangulação.

$\mathrm{Na}$ pesquisa tradicionalmente encenada, valorizamos a triangulação. Na triangulação, um pesquisador implementa diferentes métodos - como entrevistas, dados de censo e documentos - para validar os resultados. Entretanto, esses métodos possuem os mesmos pressupostos de domínio, incluindo a suposição de que existe um ponto fixo ou objeto que pode ser triangulado. Mas nos textos pós-modernistas de gêneros mistos, nós não triangulamos; nós cristalizamos. Reconhecemos que há muito mais do que três lados para se aproximar do mundo.

Proponho que o imaginário central para a validade dos textos pós-modernistas não é o triângulo - um objeto rígido, fixo, bidimensional. Em vez disso, o imaginário central é o cristal, que combina simetria e substância com uma infinita variedade de formas, substâncias, transmutações, multidimensionalidades e ângulos de aproximação. Os cristais crescem, mudam e alteram, mas não são amorfos.

Os cristais são prismas que refletem externalidades e refratam dentro de si mesmos, criando diferentes cores, padrões e matrizes, que são lançados para fora em diferentes direções, O que vemos depende de nosso ângulo de repouso, não da triangulação ou da cristalização. Nos textos de gêneros mistos pós-modernistas, passamos da geometria plana para a teoria da luz, onde a luz pode ser tanto ondas quanto partículas. 
A cristalização, sem perder a estrutura, desconstrói a ideia tradicional de validade (sentimos que não existe uma única verdade, vemos como os textos se validam) e a cristalização nos proporciona uma compreensão aprofundada, complexa e completamente parcial do tema. Paradoxalmente, sabemos mais e duvidamos do que sabemos. Engenhosamente, sabemos que há sempre mais a saber.

Vemos também este processo de cristalização em vários livros recentes de gêneros mistos. A Schoolgirl Fictions ${ }^{11}$ de Valerie Walkerdine (1990) desenvolve/ exibe o tema de que "a masculinidade e a feminilidade são ficções que assumem o posição de fato" (p.13), incorporando no livro entradas de diário, poemas, ensaios, fotográficos de si mesma, desenhos, cartoons, e transcrições anotadas. Making Stories, Making Selves: Feminist Reflections on the Holocaust ${ }^{12}$ (1993) de Ruth Linden entrelaça a autobiografia, a escrita acadêmica e as histórias de sobreviventes num prêmio da Helen Hooven Santmyer no livro Women's Studies ${ }^{13}$, que foi sua dissertação. Tales from the Field ${ }^{14}$ (1988) de John Van Maanen apresentam sua pesquisa na polícia como realista, confessional, e como uma narrativa impressionista. Troubling the Angels: Women Living with HIV/AIDS ${ }^{15}$ (1977) de Patti Lather e Chris Smithies exibe um intensa teoria, a histórias de pesquisadores, transcrições de grupos de apoio de mulheres, informações históricas e médicas, usando diagramações inovadoras no texto. The written suburb ${ }^{16}$ de John Dorst (1989) apresenta um sítio geográfico como site, imagem, ideia, discurso e uma assembleia de textos. Death at the Paraiste Cafe ${ }^{17}$ (1992) de Stephen Pfohl emprega estratégias de colagem e justaposições sincrônicas, borrando teorias críticas e formas de arte militantes.

Em algumas produções de gêneros mistos, o escritor/artista percorre livremente os tópicos, quebrando nosso senso de exterioridade de tópicos, desenvolvendo nosso senso de como o tópico e o eu são construídos. Self and the Social Sciences: Personal Essays on an Art Form ${ }^{18}$ (1991) de Susan Krieger são um exemplo soberbo. O livro é "orientado para o design", refletindo seu apego aos ceramistas de Pueblo e Georgia O'Keefe, e, como ela diz, "parece mais com um pote ou uma pintura do que com uma hipótese" (p.120). Women Native Other ${ }^{19}$ (1989) de Minh-Ha T. Trinh quebra as convenções de escrita dentro de cada um dos ensaios que compõem o livro, misturando poesia, auto-reflexão, crítica feminista, fotografias e citações que ajudam os leitores a experimentar a pós-colonialidade. l've Known Rivers: Lives of Loss and Liberation $^{20}$ (1994) de Sara Lawrence-Lightfoot usa técnicas de escrita de ficção e auto-reflexividade para contar histórias do que é ser afro-americano e profissional. Antologias também refletem esses gêneros mistos. Meu próprio livro Fields of Play: Constructing an Academic Life ${ }^{21}$ (1997) conta a história de minhas lutas intelectuais e políticas na academia através de ensaios pessoais, dramas, poemas, histórias de

\footnotetext{
11 Ficção de um colégio de garotas

12 Fazendo histórias fazendo a si mesmas: Reflexões feministas sobre o Holocausto

13 Estudos Femininos

14 Contos sobre o campo

15 Incomodando os anjos: Mulheres vivendo com HIVIAIDS

160 subúrbio escrito

17 A Morte no Café Parasita

180 Eu e as ciências sociais: Os ensaios pessoais numa forma artística

19 Outras mulheres nativas

20 Eu tenho conhecido rios: Vidas de Perda e Libertação

21 Campos de Jogo: Construindo uma Vida Acadêmica
} 
escrita, e-mails e artigos de sociologia. Antologias também apresentam gêneros mistos. Alguns exemplos são: Composing Ethnography: Alternative Forms of Qualitative Writing 22 (1996) de Carolyn Ellis e Arthur Bochner; Investigating Subjectivity: Research on Lived Experience ${ }^{23}$ (1992) de Carolyn Ellis e Michael Flaherty; Women Writing Culture ${ }^{24}$ (1995) de Ruth Behar e Deborah Gordon; a série Studies in Symbolic Interaction ${ }^{25}$; e a revista Qualitative Inquiry ${ }^{26}$.

\section{Para onde e de onde?}

O contexto pós-moderno contemporâneo em que trabalhamos como pesquisadores qualitativos é propício. Ele fornece uma oportunidade para que possamos rever, criticar e reavivar a escrita. Embora estejamos mais livres para apresentar nossos textos de diversas formas a públicos diversos, temos diferentes restrições que surgem da autoconsciência sobre as reivindicações de autoria, autoridade, verdade, validade e confiabilidade. A auto reflexividade traz à consciência algumas das complexas agendas políticas/ideológicas escondidas em nossa escrita. As reivindicações de verdade são menos facilmente validadas agora; Desejos de falar por outros são suspeitos. A maior liberdade para experimentar com a forma textual, no entanto, não garante um produto melhor. As oportunidades para escrever textos dignos - livros e artigos que são "bons para ler" - são múltiplas, excitantes e exigentes, mas o trabalho é mais difícil. As garantias são menores. Há muito mais para pensarmos.

Escrever de forma tradicional não nos impede de escrever de outras maneiras para outros públicos em outros momentos (Denzin, 1994; Richardson, 1990). Não há uma maneira única - muito menos "correta" - de encenar um texto. Com o tempo úmido, o material pode ser moldado. Aprender maneiras alternativas de escrever aumenta o seu repertório e aumenta o número e tipos de público que você pode alcançar.

Quem é seu público? Quais são seus propósitos? Compreender como encenar retoricamente sua escrita aumenta suas chances de ser publicado e atingir seu público-alvo. Desconstruir as práticas tradicionais de escrita torna os escritores mais conscientes das convenções de escrita e, portanto, mais competentemente capazes de fazer escolhas.

Vejo o projeto etnográfico como humanamente situado, sempre filtrado através de olhos humanos e percepções humanas, suportando as limitações e os pontos fortes dos sentimentos humanos. A superestrutura científica está sempre apoiada na base da atividade humana, das crenças e dos entendimentos. Enfatizo a etnografia como construída através de práticas de pesquisa. As práticas de pesquisa estão preocupadas com a ampliação da compreensão. A ciência oferece algumas práticas de pesquisa, tais como a literatura, as artes criativas, o trabalho da memória (Davies, 1994; Davies et al., 1997) e a introspecção (Ellis, 1991) entre outros. Os pesquisadores têm muitas práticas das quais escolher e não devem ser limitados pelos hábitos da mente de outra pessoa.

22 Composição Etnográfica: Formas alternativas de escrita qualitativa

23 Investigações sobre a Subjetividade: Pesquisa sobre a Experiência Vivida

24 Mulheres escrevendo a cultura

25 Estudos em interação simbólica

26 Pesquisa Qualitativa 
Acredito na manutenção das etnografias PAC para sustentar padrões elevados e difíceis; a mera novidade não é suficiente. Aqui estão cinco dos critérios que eu uso quando reviso artigos ou monografias submetidas para publicação social-científica.

1. Contribuição substancial. Este trabalho contribui para a nossa compreensão da vida social? O escritor demonstra uma perspectiva social-científica profundamente aterrada (se incorporada)? Como essa perspectiva é informada na construção do texto?

2. Mérito estético. Em vez de reduzir padrões, um outro padrão é adicionado. Essa peça tem sucesso esteticamente? $O$ uso das práticas analíticas criativas abre o texto e convida a respostas interpretativas? O texto é artisticamente moldado, satisfatório, complexo e não é chato?

3. Reflexividade. O autor conhece a epistemologia pós-moderna? Como o autor chegou a escrever este texto? Como foi a informação recolhida? Existem questões éticas? Como a subjetividade do autor tem sido tanto um produtor como um produto deste texto? Existe uma auto-consciência adequada e auto-exposição para o leitor fazer julgamentos sobre o ponto de vista? Os autores se responsabilizam pelos padrões de conhecimento e contaram as pessoas que estudaram?

4. Impacto. Isso me afeta emocionalmente e/ou intelectualmente? Será que isso gera novas perguntas, me move a escrever, me move a tentar novas práticas de pesquisa, ou me move para a ação?

5. Expressa uma realidade. Este texto incorpora um sentido da experiência vivida? Parece ser verdade - uma crença de um sentido cultural, social, individual ou comunitário do "real"?

Estes são cinco dos meus critérios. A ciência é uma lente, as artes criativas outra. Vemos mais profundamente usando as duas lentes. Eu quero olhar através de ambas as lentes, para ver uma "forma de arte de ciência social".

Discordo fortemente daqueles que afirmam que a etnografia deve ser uma "guilda da ciência", um "ofício" com "regras tácitas", aprendizes, segredos comerciais, trabalhadores responsáveis (i.e. professores), que promulgam regras que verificam "pretensões artísticas e excessos" (Richardson, 1996b, Schwalbe, 1995). Essa visão medieval limita a exploração etnográfica, patrulha os limites do pensamento intelectual e alinha a pesquisa qualitativa ideologicamente com aqueles que disciplinariam e puniriam as ideias pós-modernas dentro da ciência social. O policiamento, porém, é sempre sobre corpos. É sempre sobre pessoas reais. Se a visão medieval triunfa, o que as pessoas reais vivem será, provavelmente, excluído?

O que aprendi com meus ensinamentos e conversas com colegas é o seguinte: minorias dentro da academia, incluindo estudantes étnicos e raciais, pós-coloniais, gays e lésbicas, fisicamente desafiados, estudantes que estão retornando, acham que as práticas analíticas criativas estão acenando. Esses pesquisadores desejam a oportunidade de serem responsáveis perante a guilda, honrando suas responsabilidades com suas tradições, culturas e seu senso de vida significativo.

Acolher esses pesquisadores cria uma comunidade enriquecida, diversificada, socialmente comprometida e não hegemônica de pesquisadores qualitativos. Todos ganham - as comunidades de origem e identificação e a comunidade de pesquisa qualitativa. As implicações de raça e gênero seriam enfatizadas, não porque seria 
"politicamente corretas", mas porque raça e gênero são eixos através dos quais se construiriam mundos simbólicos e reais. Membros de mundos não-dominantes sabem disso e podem insistir para que esse conhecimento seja honrado (ver Margolis e Romero, 1998). O esbatimento das ciências humanas e sociais seria bem-vindo, não porque ele é moderno, mas porque o borrão adere mais verdadeiramente com o estilo de vida e sentido de aprendizagem de muitos. Esta nova comunidade qualitativa poderia, através de sua teoria, práticas analíticas e membros diversos, chegar além do mundo acadêmico, ensinando a todos nós sobre a injustiça social e os métodos para aliviá-la. Que pesquisador qualitativo interessado na vida social não se sentiria enriquecido pela adesão a uma comunidade culturalmente tão diversa e convidativa?

A vida etnográfica não é separável do eu. Quem somos e o que podemos ser - o que podemos estudar, como podemos escrever sobre o que estudamos - está ligado a como um sistema de conhecimento disciplina a si mesmo e a seus membros, seus métodos de autoridade sobre o assunto e seus membros. Nossa tarefa é encontrar práticas concretas através das quais possamos construir-nos como sujeitos éticos engajados na etnografia ética - estimulados a ler e a escrever.

Algumas dessas práticas são (a) o trabalho dentro do esquema teórico (sociologia do conhecimento, feminismo, teoria crítica da raça, construtivismo, pós-estruturalismo) que desafiam as bases da autoridade; (b) a escritura sobre temas que importam, pessoalmente e coletivamente; (c) o gozo - experimentando simultaneamente diferentes formatos de escrita e audiências; (d) o localizar-se em múltiplos discursos e comunidades; (e) o desenvolver a instrução crítica; (f) o encontro de maneiras de escrever/apresentar/ensinar que sejam menos hierárquicas e unívocas; $(g)$ a revelação de segredos institucionais; (h) a utilização de cargos de autoridade para aumentar a diversidade, tanto em nomeações acadêmicas quanto em publicações em periódicos; (i) a auto-reflexividade; (j) o ceder à sincronicidade; (k) o perguntar o que você quer, como um gato; (l) o não vacilar de onde a escrita leva você, emocionalmente ou espiritualmente; e $(m)$ o honrar a incorporação e a espacialidade de seus trabalhos.

O que as práticas analíticas criativas na etnografia eventualmente produzirão, eu não sei. Mas, eu sei, que o terreno foi estacado, a fundação estabelecida, andaimes erguidos e colonos aventureiros e diversos se mudaram para ele.

\section{Referências}

Agger, B. (1990). The decline of discourse: Reading, writing and resistance in postmodem capitalism. Bristol, PA: Falmer.

Baff, S.J. (1997). "Realism and naturalism and dead dudes": Talking about literature in $11^{\text {th }}$ grade English. Qualitative Inquiry, 3, 468-490.

Balzac, R. de (1965). Preface to The Human Comedy, from At the Sign of the Cat and Raeket (C. Bell, Trans., 1897; original work published 1842). In R. Ellman and C. Feidelson, Jr. (Eds.), The modem tradition: Backgrounds of modem literature (pp. 246-254). New York: Oxford University Press. 
Banks, A., \& S. Banks. (1998). Fiction and social research: By fire or ice. Walnut Creek, CA: AltaMira Press.

Behar, R (1996). The vulnerable observer: Anthropology that breaks your heart. Boston: Beacon Press.

Behar, R, \& Gordon, D. (Eds.) (1995). Women writing culture. Berkeley, CA: University of Caledonia Press.

Brady, L (Ed). (1991). Anthropological poetics. Savage, MD: Rowman \& Littlefield.

Brodkey, L. (1987). Academia writing as social practice. Philadelphia: Temple University Press.

Brown, K.M. (1991). Mama Laia: A Vodou priestess in Brooklyn. Berkeley, CA: University of California Press.

Brown, R.H. (1977). A poetic for sociology. Cambridge, MA: Cambridge University Press.

Bruner, E.M. (1996). My life in an ashram. Qualitative Inquiry, 2, 300-319.

Cherry, K. (1995). The best years of their lives: A portrait of a residential home for people with AIDS. Symbolic Interaction, 18, 463-486.

Church, K. (1995). Forbidden narratives: Critical autobiography as social science. Newark, NJ: Grodon \& Breach.

Clifford, J. (1986). Introduction: Partial truths. In J. Clifford \& G.E. Marcus (Eds.), Writing culture: The poetics and polities of ethnography. Berkeley, CA: University of California Press.

Clifford, J., \& Marcus, G.E. (Eds.) (1986). Writing culture: The poetics and polities of ethnography. Berkeley, CA: University of California Press.

Clough, P.T. (1992). The end (s) of ethnography: From realism to social criticism. Thousand Oaks, CA: Sage Publishing.

Crawford, M.A. (1951). Introduction. In Old gariot (pp. 1-8). New York: Penguin Books.

Davies, B. (1989). Poststructuralist and feminist tales: Preschool children. St. Leonard's, Australia: Allen \& Unwin.

Davies, B. (1994). Poststructuralist theory and classroom practice. Geelong, Australia: Deakin University Press. 
Davies, B. et al. (1997) Ruptures in the skin of silence: A collective biography. Hecate: A Woman's Interdisciplinary Journal, 23, 62-79.

Denzin, N.K. (1986). A postmodern social theory. Sociological Theory, 4, 194-204.

Denzin, N.K. (1991). Images of postmodern society. Thousand Oaks, CA: Sage.

Denzin, N.K. (1994). Evaluating qualitative research in the poststructural moment: The lessons James Joyce teaches use Qualitative Studies in Education, 7, 295-308.

Denzin, N.K. (1995). The cinematic society: The voyeur's case. Thousand Oaks, CA: Sage.

Denzin, N.K. (1997). Interpretive ethnography: Ethnographic practices for the 21st century. Thousand Oaks, CA: Sage.

DeShazer, M.K. (1986). Inspiring women.' Reimagining the muse. New York: Perganon.

Diarnond, S. (1985). Totems. New York: Open BookJStation Hill.

Diversi, M. (1998). Late for school. Waikato Journal of Education, 4, 78-86.

Dorst, ID. (1989). The written suburb: An American site, an ethnographic dilemma. Philadelphia: University of Pennsylvania Press.

Ellis, C. (1991). Sociological introspection and emotional experience. Symbolic Interaction, 14, 23-50.

Ellis, C. (1993). Telling the story of sudden death. The Sociological Quarterly, 34, 711-730.

Ellis, C, \& Bochner, A. (1991). Telling and performing personal stories: The constraints of choice in abortion. In C. Ellis \& M.G. Flaherty (Eds.), Investigating subjectivity: Research on lived experience. Thousand Oaks, CA: Sage.

Ellis, C., \& Bochner, A. (Eds.) (1996). Composing ethnography: Alternative forms of qualitative writing. Walnut Creek, CA: Altamira Press.

Ellis, C., \& Flaherty, M.G. (Eds.) (1992). Investigating subjectivity: Research on lived experience. Thousand Oaks, CA: Sage.

Erikson, K.T. (1976). Everything in its path: Destruction of the community in the Buffalo Creek Flood. New York: Simon \& Shuster.

Fine, M. (1992). Disruptive voices: The possibility of feminist research. Ann Arbor, MI: The University of Michigan Press. 
Fishkin, S.E (1985). From fact to fiction: Journalism and imaginative writing in America. Baltimore, MD: John Hopkins University Press.

Frohock, E (1992). Healing powers. Chicago: University of Chicago Press.

Glesne, C.E. (1997). That rare feeling: Re-presenting research through poetic transcription. Qualitative Inquiry, 3, 202-221.

Hooks, B. (1990). Yearning: Race, gender, and cultural politics. Boston: South End Press.

Hurston, Z.N. (1991). Dust tracks on a road. New York: HarperCollins. (Original work published 1942)

Jones, S.H. (1998). Kaleidoscope notes; Writing women's music and organizational culture. Walnut Creek, CA: Altamira Press.

Kaufrnan, S. (1986). The ageless self: Sources of meaning in later life. Madison, WI: University of Wisconsin Press.

Krieger, S. (1991). Social science and the self: Personal essays on an art form New Brunswick, NJ: Rutgers University Press.

Lather, P. (1991). Getting smart: Feminist research and pedagogy with/in the postmodern. New York: Routledge.

Lather, P., \& Smithies, C. (1997). Troubling the angels: Women living with HIV/AIDS. Boulder, CO: Westview.

Lawrence-Lightfoot, S. (1994). l've known rivers: Lives of loss and liberation. Boston: Addison- Wesley.

Levine, D.N. (1985). The light from ambiguity: Essays in social and cultural theory. Chicago: University of Chicago Press.

Linden, R.R. (1993). Making stories, making selves: Feminist rejections on the Holocaust. Columbus, $\mathrm{OH}$ : The Ohio State University.

Lockridge, E. (1987). F. Scott Fitzgerald's Tromoe l'Oeil and The Great Gatsby's buried plot. The Journal of Narrative Technique, 17,163-83.

Lyotard, J.-F. (1984). The postmodern condition: A report on knowledge (G. Bennington \& G. Masurni, Trans.). Minneapolis, MN: University of Minnesota Press. (Original work published 1979).

Mischler, E.G. (1989). Research interviewing: Context and narrative. Cambridge, MA: Harvard University Press. 
Margolis, E., \& Romero, M. (1998). The departrnent is very male, very white, very old, and very conservative: The functioning of the hidden curriculum in graduate sociology departments. Harvard Educational Review, 68,1-32.

McCall, M., \& Becker, H. (1990). Performance science. Social Problems, 32,117-32.

Mienczakowski, J. (1996). An ethnographic act: The construction of consensual theater. In C. Ellis \&A. Bochner (Eds.), Composing ethnography: Alternative forms of qualitative writing. Walnut Creek, CA: Altamira Press.

Nicholson, L.J. (Ed.) (1990). Feminism/postmodernism. New York: Routledge. Paget, M. (1990). Performing the text. Journal of Contemporary Ethnography 19,136-55.

Pfohl, S.J. (1992). Death at the Parasite Cafe: Social science (fictions) and the postmodern. New York: St. Martins Press.

Richardson, L. (1985). The new other woman: Contemporary single women in affairs with married men. New York: The Free Press.

Richardson, L. (1990). Writing strategies: Reaching diverse audiences. Thousand Oaks, CA: Sage.

Richardson, L. (1993). The case of the skipped line: Poetics, dramatics and transgressive validity. The Sociological Quarterly, 34, 695-710.

Richardson, L. (1995). Writing-stories: Co-authoring “The sea monster,' a writing-story. Qualitative Inquiry, 1, 189-203.

Richardson, L. (1996a). Educational Birds. Journal of Contemporary Ethnography, 25, 6-15.

Richardson, L. (1996b). A sociology of responsibility. Qualitative research, 19, 519-524.

Richardson, L. (1997). Fields of play: Constructing an academic life. New Brunswick, NJ: Rutgers University Press.

Richardson, L., \& Lockridge, E. (1991). The sea monster: An ethnographic drama. Symbolic Interaction, 14, 335-40.

Rubin, L.B. (1976). Worlds of pain: Life in the working-class family. New York: Basic Books. St. Pierre, E.A. (1997). Nomadic inquiry in the smooth spaces of the field: A preface. Qualitative Studies in Education, 10,175-189.

Schwalbe, M. (1995). The responsibilities of sociological poets. Qualitative Sociology, 18, 393-412. 
Simons, H.W. (1990). Rhetoric in the human sciences. London: Sage.

Stack, C.B. (1974). Ali our kin: Strategies for survival in a black community. New York: Harper \& Row.

Stoller, P. (1989). Taste of ethnographic things: The senses in anthropology. Philadelphia: University of Pennsylvania Press.

Tedlock, D. (1983). The spoken word and the work of interpretation. Philadelphia: University of Pennsylvania Press.

Trinh, T.M-H. (1989). Woman, native, other: Writing postcoloniality and feminism Bloornington, IN: Indiana University Press.

Tumer, V. and Bruner, E.M. (Eds.) (1986). The anthropology of experience. Champaign, IL: University of Illinois Press.

Ulmer, G. (1989). Teletheory: Grammatology in the age of video. New York: Routledge. Van Maanen, J. (1988). Tales of the field: On writing ethnography. Chicago: University of Chicago Press.

Van Maanen, J. (Ed.) (1995). Representation in ethnography. Thousand Oaks, CA: Sage.

Walkerdine, V. (1990). School girl fictions. London: Verso.

Weedon, C. (1987). Feminist practice \&poststructuralist theory. New York: Basil Blackwell.

Whyte, W.F. (1943). Street comer society: The social structure of an Italian slum. Chicago: University of Chicago Press.

Zola, E. (1965). The novel as social science. In R. Ellman \& C. Feidelson, Jr. (Eds.), The modem tradition: Backgrounds of modem

\section{Agradecimentos}

Agradeço a Emest Lockridge por muitas discussões sobre esse material. Agradeço também a Arthur Bochner, a Norman Denzin, a Carolyn Ellis, a Michelle Fine, a Patti Lather, a Yvonna Lincoln, a Meaghan Morris e a John Van Maanen por suas críticas generosas e valiosas a trabalhos anteriores. Finalmente, estou grato aos muitos alunos que me disseram que encontraram versões anteriores deste trabalho úteis; eles me deram a energia e a vontade de revisá-lo.

Recebido em: 21/05/2018

Aprovado em: 16/06/2018 